\title{
Improved methodologies for continuous-flow analysis of stable water isotopes in ice cores
}

\author{
Tyler R. Jones ${ }^{1}$, James W. C. White ${ }^{2}$, Eric J. Steig ${ }^{3}$, Bruce H. Vaughn ${ }^{1}$, Valerie Morris ${ }^{1}$, Vasileios Gkinis ${ }^{4}$, \\ Bradley R. Markle ${ }^{3}$, and Spruce W. Schoenemann ${ }^{3}$ \\ ${ }^{1}$ Institute of Arctic and Alpine Research, University of Colorado, Boulder, CO 80309-0450, USA \\ ${ }^{2}$ Institute of Arctic and Alpine Research and Department of Geological Sciences, University of Colorado, \\ Boulder, CO 80309-0450, USA \\ ${ }^{3}$ Department of Earth and Space Sciences, University of Washington, Seattle, Washington 98195-1310, USA \\ ${ }^{4}$ Centre for Ice and Climate, Niels Bohr Institute, University of Copenhagen, Copenhagen, Denmark \\ Correspondence to: Tyler R. Jones (tyler.jones@ colorado.edu)
}

Received: 6 April 2016 - Discussion started: 26 July 2016

Revised: 22 January 2017 - Accepted: 30 January 2017 - Published: 27 February 2017

\begin{abstract}
Water isotopes in ice cores are used as a climate proxy for local temperature and regional atmospheric circulation as well as evaporative conditions in moisture source regions. Traditional measurements of water isotopes have been achieved using magnetic sector isotope ratio mass spectrometry (IRMS). However, a number of recent studies have shown that laser absorption spectrometry (LAS) performs as well or better than IRMS. The new LAS technology has been combined with continuous-flow analysis (CFA) to improve data density and sample throughput in numerous prior ice coring projects. Here, we present a comparable semiautomated LAS-CFA system for measuring high-resolution water isotopes of ice cores. We outline new methods for partitioning both system precision and mixing length into liquid and vapor components - useful measures for defining and improving the overall performance of the system. Critically, these methods take into account the uncertainty of depth registration that is not present in IRMS nor fully accounted for in other CFA studies. These analyses are achieved using samples from a South Pole firn core, a Greenland ice core, and the West Antarctic Ice Sheet (WAIS) Divide ice core. The measurement system utilizes a 16-position carousel contained in a freezer to consecutively deliver $\sim 1 \mathrm{~m} \times 1.3 \mathrm{~cm}^{2}$ ice sticks to a temperature-controlled melt head, where the ice is converted to a continuous liquid stream and eventually vaporized using a concentric nebulizer for isotopic analysis. An integrated delivery system for water isotope standards is used for calibration to the Vienna Standard Mean Ocean Water
\end{abstract}

(VSMOW) scale, and depth registration is achieved using a precise overhead laser distance device with an uncertainty of $\pm 0.2 \mathrm{~mm}$. As an added check on the system, we perform inter-lab LAS comparisons using WAIS Divide ice samples, a corroboratory step not taken in prior CFA studies. The overall results are important for substantiating data obtained from LAS-CFA systems, including optimizing liquid and vapor mixing lengths, determining melt rates for ice cores with different accumulation and thinning histories, and removing system-wide mixing effects that are convolved with the natural diffusional signal that results primarily from water molecule diffusion in the firn column.

\section{Introduction}

The measurement of water isotopes in ice cores provides records of past hydrologic cycle variability (Dansgaard, 1964). The parameters $\delta \mathrm{D}$ and $\delta^{18} \mathrm{O}$ are proxies for both local temperature and regional atmospheric circulation, while the second-order parameter deuterium excess has been used to obtain information about source water evaporative conditions (temperature, humidity, and wind speed), as well as changes in the location of moisture source regions (Jouzel and Merlivat, 1984; Jouzel et al., 1997; Johnsen et al., 2001; Kavanaugh and Cuffey, 2003; Steig et al., 2013). These parameters have routinely been analyzed since the origins of ice core science, first in a precipitation experiment in Copen- 
hagen in 1952, then on the visible layers of icebergs in the North Atlantic, and later in the Camp Century ice core (described in Dansgaard, 2005). Since these early experiments, a large collection of ice core water isotope records have been recovered from the Greenland Ice Sheet, the Antarctic Ice Sheet, and many high-latitude and/or high-altitude ice caps. These records have been instrumental in understanding climate change over annual to millennial timescales, including abrupt climate change events (Dansgaard et al., 1989; Grootes et al., 1993; Alley, 2000), the bipolar seesaw (WAIS Divide Project Members, 2015), and glacial-interglacial cycles (Petit et al., 1999).

Traditional measurements of water isotopes have been accomplished using customized preparation systems and isotope ratio mass spectrometry (IRMS; see a full list of abbreviations in Table 1). Typically, water samples are analyzed discretely using 3-5 cm intervals of ice. Isotopic ratios of oxygen are usually obtained using a $\mathrm{CO}_{2}-\mathrm{H}_{2} \mathrm{O}$ equilibration method (Epstein et al., 1953; Craig et al., 1963). For hydrogen isotopes, a variety of methods have been used, including $\mathrm{H}_{2}-\mathrm{H}_{2} \mathrm{O}$ equilibration using a platinum catalyst and reduction of water with uranium, zinc, or chromium (Bigelseisen et al., 1952; Bond, 1968; Coleman et al., 1982; Coplen et al., 1991; Vaughn et al., 1998; Huber and Leuenberger, 2003).

Advances in high-precision laser absorption spectroscopy (LAS) methods are now widely adopted as an alternative to IRMS methods (Kerstel et al., 1999; Lis et al., 2008; Gupta et al., 2009; Brand et al., 2009). There are currently two main LAS methods used: cavity ring-down laser spectroscopy (CRDS; manufactured by Picarro, Inc.) and off-axis integrated cavity output laser spectroscopy (OA-ICOS; manufactured by Los Gatos Research). The CRDS method (utilized in this study) requires the input of water vapor into a detection cavity that confines and reflects laser pulses using a series of mirrors. By comparing the extinction of a laser pulse at different frequencies in an empty cavity and in a cavity filled with water vapor, water isotope concentrations can be determined (Crosson, 2008).

Systems have been developed that continuously deliver water vapor into LAS measurement devices. The technique, known as continuous-flow analysis (CFA), is accomplished by slowly melting a solid ice stick into a continuous liquid stream, which is then vaporized and injected into the LAS instrument. Gkinis et al. $(2010,2011)$ established the CFA framework for water isotope analysis using LAS. In particular, Gkinis reproduced traditional IRMS water isotope measurements in Greenland ice using a Picarro L1102-i CRDS instrument. Gkinis found that the precision of hydrogen and oxygen isotope measurements was comparable to IRMS. Substantial increases in depth resolution and shorter analysis time were realized. Maselli et al. (2013) expanded on Gkinis' technique by testing multiple new-generation Picarro devices (L2120-i and L2130-i) and found similar results. Later, Emanuelsson et al. (2015) used OA-ICOS to continuously analyze water samples from an ice core, achieving reductions in isotopic step-change response time and memory effects. Other water isotope CFA techniques (not considered in this paper) have utilized a platinum catalyst for continuous mass spectrometry measurements (Huber and Leuenberger, 2005) or a thermal conversion elemental analyzer (TC/EA) coupled to a mass spectrometer (Sharp et al., 2001). CFA has also widely been used for chemical measurements in ice cores (e.g., Röthlisberger, 2000; Osterberg et al., 2006; Bigler et al., 2011; and Rhodes et al., 2013).

\subsection{Goals of this study}

In this study, we present a semi-automated water isotope CRDS-CFA system developed at the Institute of Arctic and Alpine Research (INSTAAR) Stable Isotope Lab (SIL). We analyze $\delta \mathrm{D}, \delta^{18} \mathrm{O}$, and deuterium excess values in a series of ice samples from Greenland and Antarctica. New methods are used to test the precision of the isotopic data. We present "full-system" precision tests using replicate ice samples to account for multiple sources of uncertainty on the CRDSCFA system. We then present steps to create isotopically distinct ice sticks to evaluate the impulse response of the system, which yields a CFA system mixing length. The mixing length is a measure of $1 \sigma$ displacement of water molecules from their original position in the solid ice sample. This is important for two reasons: (1) the system mixing length needs to be distinguished from the effects of diffusion occurring naturally in the ice sheet, and (2) based on the mixing length, system flow rates and the total mixing volume can be adjusted to prevent isotopic signal attenuation in ice cores from low-accumulation drill sites. Based on the system wide mixing length, we propose a way to separate isotopic mixing effects in the liquid and vapor phase. This test is important for CFA systems that have complicated liquid-phase components, such as those systems analyzing multiple chemical species that require extra lengths of tubing to transport liquid water. We then perform inter-lab and inter-system isotopic testing of firn ice and solid ice to determine how the CRDS-CFA system performs with ice of different densities. The results of this study will be used in the analysis of the West Antarctic Ice Sheet (WAIS) Divide ice core (WDC), the South Pole ice core (SPICE), and other ice cores in the future.

\section{Data processing methodologies and evaluation}

\subsection{Water isotope measurements}

The ratio of heavy to light water isotopes in a water sample is expressed in delta notation (Epstein, 1953; Mook, 2000) relative to Vienna Standard Mean Ocean Water, where VS- 
Table 1. List of abbreviations used in this paper.

\begin{tabular}{lll}
\hline Type & Name & Abbreviation \\
\hline Ice core drilling sites & West Antarctic Ice Sheet (WAIS) Divide ice core & WDC \\
& South Pole ice core & SPICE \\
\hline Measurement devices & Isotope ratio mass spectrometry & IRMS \\
& Laser absorption spectrometry & LAS \\
& Continuous-flow analysis & CFA \\
& Cavity ring-down laser spectroscopy & CRDS \\
& Off-axis integrated cavity output laser spectroscopy & OA-ICOS \\
\hline \multirow{2}{*}{ Water isotope standards } & International Atomic Energy Agency & IAEA \\
& Vienna Standard Mean Ocean Water & VSMOW \\
& Standard light Antarctic precipitation & SLAP \\
& Greenland Ice Sheet precipitation & GISP \\
& Boulder standard water & BSW \\
& Antarctic standard water & ASW \\
& Greenland standard water & GSW \\
& Polar standard water & PSW \\
\hline System performance & Allan variance & AVAR \\
& Cumulative distribution function & CDF \\
& Laboratory water isotope standards & LS \\
& Greenland test ice & GTI \\
& Isotopically homogenous water & IHW \\
& South Pole firn & SPF \\
\hline
\end{tabular}

MOW has been set to $0 \%$ by the International Atomic Energy Agency (IAEA):

$\delta_{\text {sample }}=\left[\left(\frac{R_{\text {sample }}}{R_{\text {VSMOW }}}\right)-1\right]$,

where $R$ is the isotopic ratio ${ }^{18} \mathrm{O} /{ }^{16} \mathrm{O}$ or D / $\mathrm{H}$ (i.e., ${ }^{2} \mathrm{H} /{ }^{1} \mathrm{H}$ ) in the sample or VSMOW. The $\delta$ values $\left(\delta^{18} \mathrm{O}\right.$ or $\left.\delta \mathrm{D}\right)$ are thus deviations from VSMOW, usually expressed in parts per thousand (per mil or \%o). The deuterium excess parameter (dxs) is defined as function of both hydrogen and oxygen isotope ratios:

$\mathrm{dxs}=\delta \mathrm{D}-8 \cdot \delta^{18} \mathrm{O}$.

The dxs variable is not a direct isotopic measurement, but rather it is calculated from the direct measurement of oxygen and hydrogen isotope ratios. The precise calculation of dxs (\%o) has historically been challenging because IRMS methodology requires that oxygen and hydrogen water isotope ratios be analyzed on separate systems using separate samples, which could increase uncertainty. The CRDS-CFA technique removes the potential for multi-system uncertainty because both isotopic values are measured simultaneously on a single sample with the same system.

\subsection{Experimental system}

The CRDS-CFA system is composed of three parts: (1) the ice core melting component, (2) the liquid-to-gas conversion component, and (3) the isotopic analyzer. A full system schematic is shown in Fig. 1. The ice core melting component can accommodate 16 sticks of ice that measure $\sim 1 \mathrm{~m} \times 1.3 \mathrm{~cm} \times 1.3 \mathrm{~cm}$ (each stored in $1.9 \mathrm{~cm} \times 1.9 \mathrm{~cm}$ acrylic tubes) and that are loaded vertically into a rotating carousel contained in a freezer. Using a computercontrolled stepper motor (Parker ViX), the carousel rotates individual ice sticks over an aluminum melt head. The melt head $(51.0 \mathrm{~mm} \times 51.0 \mathrm{~mm} \times 12.6 \mathrm{~mm})$ is $\mathrm{ma}$ chined with $2 \mathrm{~mm}$ concentric square catchments that channel meltwater into a small drain. To regulate temperature, the melt head is bolted to an aluminum heater block $(51.0 \mathrm{~mm} \times 51.0 \mathrm{~mm} \times 45.8 \mathrm{~mm})$ that is maintained at $14.6 \pm 0.1^{\circ} \mathrm{C}$ by internally circulating dilute propylene glycol from a $6 \mathrm{~L}$ temperature-controlled bath. To increase the thermal conductivity between the melt head and heater block, a layer of polysynthetic silver thermal compound was applied to the interface prior to assembly. Traditionally, melt head temperatures have been controlled with electric resistive heaters that act on the mass of the heater block alone. Temperature control with the $6 \mathrm{~L}$ circulating bath provides 19-times-greater thermal mass, allowing for greater temperature stability and therefore more consistent melt rates. At $14.6^{\circ} \mathrm{C}$, the $13 \mathrm{~mm}^{2}$ ice sticks typically melt at an average 


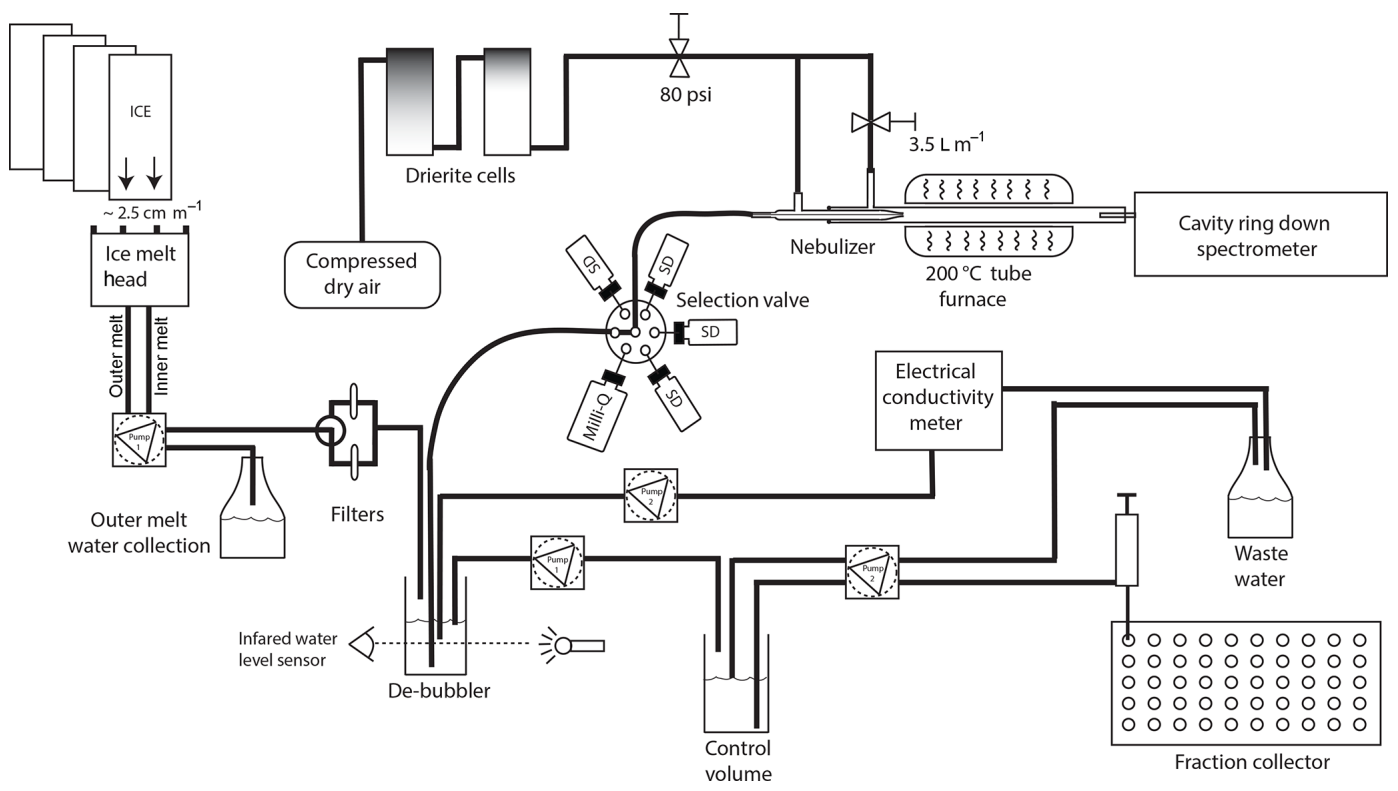

Figure 1. The INSTAAR CRDS-CFA system, showing sample flow from the ice melt head through the filter block and debubbler and onto the Valco stream selection valve, nebulizer, furnace, and Picarro L-2130-i CRDS instrument.

rate of $2.5 \mathrm{~cm} \mathrm{~min}^{-1}$. This melt rate can be increased or decreased by changing the temperature of the melt head. To prevent ice sticks from wedging against the acrylic tube during ice melt, we affix small vibrating devices to the tubes, where vibrational frequency is controlled by a variable DC power supply. A laser distance device tracks the rate at which the ice stick melts and decreases in length, with an uncertainty of $\pm 0.2 \mathrm{~mm}$ (Dimetix FLS-CH-10, Dimetix AG, Switzerland). The remote measurement of the laser allows for immediate change of ice over the melt head without reconfiguration of any mechanical measurement device.

For the liquid-to-gas conversion component of the system, liquid water is drawn away from the melt head interface using peristaltic pumps (Masterflex L/S 7534-04). Liquid water from the outer square catchment of the melt head is collected for other purposes. The inner square catchment is pumped at a rate matching that of the ice stick melt. This liquid water is pushed through an $8 \mu \mathrm{m}$ disposable filter backed by a $10 \mu \mathrm{m}$ PEEK frit (IDEX A-411). The liquid water is pushed through filters to allow for ice with ash and dust layers to be analyzed without compromising the system.

The filtered water then enters a $2 \mathrm{~mL}$ open-top glass vial where bubbles can escape (debubbler). The flow rate into the debubbler is $3.1 \mathrm{~m} \mathrm{~min}^{-1}$. An overflow tube, kept at a height of $6 \mathrm{~mm}$ from the bottom of the vial, regulates the height of the water. The vial has an inner diameter of $9.96 \mathrm{~mm}$. A portion of the debubbled water is used as primary flow (i.e., for isotopic measurements), which is aspirated from the debubbler through a $0.0625^{\prime \prime}$ OD, $0.020^{\prime \prime}$ ID tubing via a selector valve (VICI Cheminert 10P-0392L). The primary flow rate is $0.1 \mathrm{~m} \mathrm{~min}^{-1}$. The primary water is then channeled

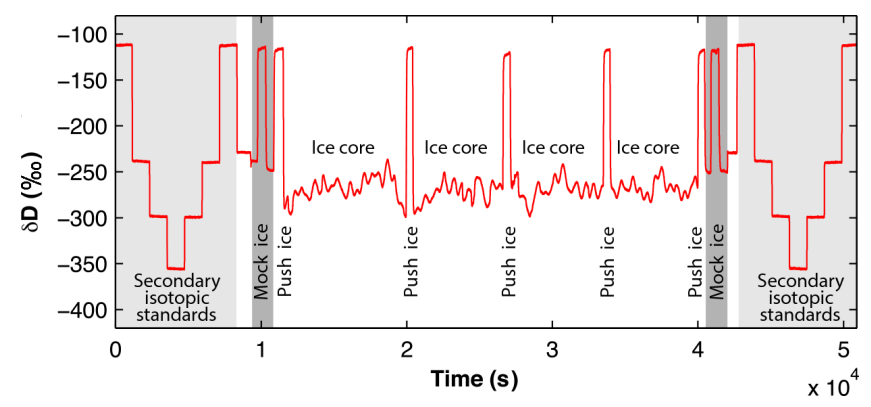

Figure 2. A typical CRDS-CFA analysis day consisting of the analysis of $12 \mathrm{~m}$ of ice core sticks from the WDC. The light grey regions show the analysis of four calibrated laboratory isotopic standards. The dark grey regions show the analysis of mock ice. The prominent white region shows the analysis of ice core sticks separated by short sections of push ice every fourth ice stick.

through a Valco six-port stream selection valve (Valco Instruments, Co. Inc.). High-pressure (80 psi) dry air is supplied to a downstream glass concentric nebulizer (Meinhard TL-HEN-150-A0.1 with $\sim 100 \mu \mathrm{m}$ ID), which converts the primary liquid water into a fine spray with a nominal droplet size of $\sim 1.5 \mu \mathrm{m}$. The concentric nebulizer was introduced in the late 1800 s by Guoy (as discussed in Witte and Barnes, 1976) and has commonly been used in inductively coupled plasma mass spectrometry. It has been in use in this system since 2011 and was first shown by Emanuelsson et al. (2015) to be useable in ice core CFA-LAS systems. The flow rate out of the nebulizer is $0.1 \mathrm{~m} \mathrm{~min}^{-1}$. Previous CFA isotopic systems have accomplished this step by pumping liquid water through a $\sim 40 \mu \mathrm{m}$ ID quartz capillary to an aluminium tee 
split where mixing with dry air and flash vaporization takes place at a temperature of $170^{\circ} \mathrm{C}$ (Gkinis et al., 2010, 2011). An advantage of the nebulizer is the wider ID, reducing the susceptibility to clogging from microparticles. The spray is directed into a $20.0 \times 1.8 \mathrm{~cm}$ Pyrex vaporizing tube that is heated to $200^{\circ} \mathrm{C}$ inside a ceramic tube furnace (Whatlow VC400N06A). Additional dry air $\left(<30 \mathrm{ppm} \mathrm{H}_{2} \mathrm{O}\right)$ is added at a rate of $\sim 3.5 \mathrm{~L} \mathrm{~min}^{-1}$ to dilute the water vapor and achieve a final water vapor content of $\sim 25000 \mathrm{ppm} \mathrm{H}_{2} \mathrm{O}$, which is within the optimal range of $20000-40000 \mathrm{ppm}_{2} \mathrm{O}$ for the Picarro L2130-i. Finally, the water vapor flows through an intake line $(3.175 \mathrm{~mm}$ OD $\times 2 \mathrm{~mm} \mathrm{ID} \times 10 \mathrm{~cm}$ stainless-steel tubing) inserted approximately $5 \mathrm{~cm}$ into the Pyrex vaporizing tube. This line is plumbed into a Picarro L2130-i analyzer by an open-split interface. Any excess vapor is vented away from the instrumentation.

At the Valco six-port stream selection valve, the primary water flow can be switched off, allowing another auxiliary port to be switched on. Each auxiliary port is connected to $30 \mathrm{~mL}$ glass vials of laboratory isotopic water standards, which can be analyzed and used for calibration of ice core measurements to international reporting standards. Additional water streams (secondary flow) are pumped from the debubbler to an electrical conductivity (EC) measurement cell (Amber Science 1056) and to a fraction collector (Gilson 215). The EC measurement allows for the comparison of chemical signatures at a known depth between labs. The fraction collector is used to archive water samples for discrete analysis and as a safeguard against system failures. It is programmed to partially fill approximately twenty-five $2 \mathrm{~mL}$ glass vials for every meter of ice melted, approximating a discrete ice sampling resolution of about $4.0 \mathrm{~cm}$.

\subsection{A typical analysis day}

On a given analysis day, we perform a sequence of measurements related to calibration and correction (Fig. 2). At the beginning and end of an analysis day, established laboratory isotopic water standards are analyzed to calibrate the ice core data. These laboratory isotopic water standards are annually calibrated to IAEA primary standards (VSMOW2, SLAP2, and GISP). We use four laboratory standards - Boulder standard water (BSW), Antarctic standard water (ASW), Greenland standard water (GSW), and Polar standard water (PSW) - that together provide a range of $\sim 244$ and $\sim 31 \%$ for $\delta \mathrm{D}$ and $\delta^{18} \mathrm{O}$, respectively. Each laboratory standard is analyzed twice for $20 \mathrm{~min}$ at the beginning and end of the day (four times total), except for PSW, which is analyzed only two times total. Table 2 contains a summary of isotopic standards.

To characterize isotopic mixing throughout the system, three small $\left(20 \mathrm{~cm} \times 13 \mathrm{~mm}^{2}\right)$ sections of laboratoryprepared ice are made from batches of isotopically distinct waters with $\delta \mathrm{D}$ values of approximately $-240 \%$ o for the first and third sections and $-120 \%$ for the second section (hereafter referred to as mock ice). The mock ice is created by filling lay-flat tubing with isotopically homogenous water (IHW), freezing the water at $-60^{\circ} \mathrm{C}$ in chilled ethanol to minimize fractionation, and cutting the ice into small sections using a band saw. The mock ice is analyzed twice per day at the beginning and end of an ice core melt sequence. Each instance of mock ice analysis is used to determine how the CRDS-CFA system is responding to an instantaneous step change in isotopic values (in this case, a change from -240 to $-120 \%$, and vice versa). This mixing effect can be quantified using transfer and impulse functions, which we discuss later in this paper.

An ice core melt sequence occurs in between analysis of laboratory isotopic water standards and mock ice. Key variables are closely monitored during this time, including water concentration in the Picarro instrument, the melt rate, and depth registration. During the ice core melt sequence, every set of four ice cores is separated by $20 \mathrm{~cm}$ sections of isotopically homogenous ice with a $\delta \mathrm{D}$ value of about $-115 \%$ o (hereafter referred to as push ice). The push ice isotopic value is much heavier than the surrounding ice core samples to ensure that they can be easily distinguished from each other. The push ice also maintains a consistent thermal load on the melt head and consistent water vapor delivery to the Picarro during routine maintenance tasks that include changing the filters and cleaning the melt head.

\subsection{Post-measurement data processing}

A graphical user interface (GUI) developed in Python is used to automate procedures and collect auxiliary data related to carousel positioning, active Valco port, ice core depth registration, quality control (e.g., water level in the debubbler and melt rate), electrical conductivity, and commenting. These auxiliary data are collected using serial ports via a Moxa UPort 1610-8, and all data are recorded at the same data frequency as the isotopic data generated by the Picarro L2130i (in this case, at approximately $\sim 1.18 \mathrm{~Hz}$ intervals; $0.85 \mathrm{~s}$ intervals). With the use of an algorithm supplied by Picarro Inc., the ancillary data are exported continuously to a raw text file along with data from the CRDS. The raw data are then post-processed offline by a separate semi-automated Python script.

During post-measurement data processing, we first identify and separate various analysis sections (e.g., laboratory standards, mock ice, push ice, and ice cores) using integer values in a comment field (e.g., mock ice section are commented "159", while ice core sections are commented "175"). For every ice core section preceded by push ice, we assign an initial depth to the ice core section at the minimum derivative of the isotopic step change. This effectively marks the mid-point of the isotopic step change and corresponds to the point when ice core isotopic values begin to dominate the preceding push ice signal. We tested and verified this depth assignment scheme using discrete samples of the same ice sections analyzed on the CRDS-CFA system. 
Table 2. Water isotope standards in units of per mil (\%o). The laboratory standards (BSW, ASW, GSW, and PSW) were calibrated to primary standards (VSMOW2, SLAP2, and GISP) in March 2010. The primary standards are reported with errors given by the IAEA. The laboratory standards are reported with a precision value given by the average standard deviation $(1 \sigma)$ of multiple isotopic determinations across multiple analysis platforms (IRMS and CRDS). In parentheses, the combined uncertainty of the laboratory standard and each primary standard is given, added in quadrature.

\begin{tabular}{lrrrr}
\hline Standards & $\delta \mathrm{D}$ & $\delta \mathrm{D}$ uncertainty & $\delta^{18} \mathrm{O}$ & $\delta^{18} \mathrm{O}$ uncertainty \\
\hline VSMOW2 & 0 & 0.3 & 0 & 0.02 \\
SLAP2 & -427.5 & 0.3 & -55.5 & 0.02 \\
GISP & -189.5 & 1.2 & -24.76 & 0.09 \\
BSW & -111.8 & $0.2(1.3)$ & -14.19 & $0.02(0.10)$ \\
ASW & -239.3 & $0.3(1.3)$ & -30.35 & $0.04(0.10)$ \\
GSW & -298.7 & $0.2(1.3)$ & -38.09 & $0.03(0.10)$ \\
PSW & -355.6 & $0.2(1.3)$ & -45.43 & $0.05(0.11)$ \\
\hline
\end{tabular}

\subsubsection{Isotope calibration}

Raw values from the CRDS system require calibration to known values of isotopic laboratory standards (as described in Sect. 2.3). Since isotopic mixing effects in the CRDS-CFA impede instrument response to the large and abrupt changes in laboratory standards, we use the average of the last $5 \mathrm{~min}$ of a 20 min total analysis to minimize the mixing effect (discussed further in Sect. 2.4.3). The "measured" (i.e., raw) values are plotted versus their "known" (i.e., assigned) VSMOW2 calibrated values. From the plot of measured ( $y$ axis) vs. known ( $x$ axis) values, a linear regression is used to define a calibration slope ( $\left.m_{\text {calibrated }}\right)$ and $y$ intercept $\left(b_{\text {calibrated }}\right)$. We then correct the GSW isotopic standard using the following equation:

$x_{\text {corrected }}=\frac{y_{\text {measured }}-b_{\text {calibrated }}}{m_{\text {calibrated }}}$,

where $y_{\text {measured }}$ is the averaged GSW value (as described above) measured on the CRDS-CFA system and $x_{\text {corrected }}$ is the GSW value calibrated to the VSMOW2-SLAP2 scale. This same calibration is done for all ice core isotopic measurements.

\subsubsection{System performance}

In addition to calibration, we also use the laboratory isotopic standards to define measures of precision and bias for the CRDS-CFA system downstream of the Valco stream selection valve. These values can be tracked through time as a performance indicator of the system. Precision is defined as the degree of internal agreement among independent measurements made under specific conditions, while bias is defined as the difference of the test results and an accepted reference value. In this case, the precision (downstream of the selector valve) is determined by taking the average standard deviation of each of the last $5 \mathrm{~min}$ of each 20 min laboratory standard run, while the bias (downstream of the selector valve) is defined as the difference of the measured GSW value from its
Table 3. Selected Allan deviation values (\%o) for a $7 \mathrm{~h}$ analysis of isotopically homogenous water on the CRDS-CFA system.

\begin{tabular}{lrr}
\hline Integration time $(\mathrm{s})$ & $\delta \mathrm{D}$ & $\delta^{18} \mathrm{O}$ \\
\hline 10 & 0.1 & 0.063 \\
60 & 0.045 & 0.026 \\
600 & 0.022 & 0.01 \\
3600 & 0.017 & 0.009 \\
\hline
\end{tabular}

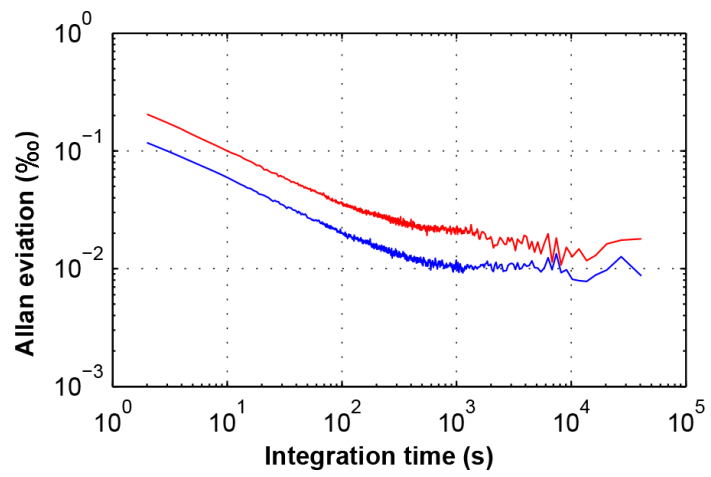

Figure 3. A $7 \mathrm{~h}$ analysis of Allan deviation for $\delta \mathrm{D}$ (red) and $\delta^{18} \mathrm{O}$ (blue) on the CRDS-CFA using isotopically homogenous water vapor.

known value. Over a period of 216 measurement days, the average precision and average bias for $\delta \mathrm{D}$ were $0.25 \pm 0.04$ and $0.40 \pm 0.12 \% o(1 \sigma)$, respectively. For $\delta^{18} \mathrm{O}$, the average precision and average bias values were $0.03 \pm 0.02$ and $-0.01 \pm 0.02 \%$ o $(1 \sigma)$, respectively. In Sect. 3, we define a precision value that takes into account all components of the CRDS-CFA system downstream of the melt head.

The stability of the Picarro CRDS analyzer is determined by tests of Allan variance (Allan, 1966), which provides a measure of the intrinsic noise in a measurement system as a function of the integration time (i.e., the amount of time 
a parcel of vapor is present in the laser cavity). The Allan variance is defined as

$\operatorname{AVAR}^{2}(\tau)=\frac{1}{2(n-1)} \sum_{i=1}^{n-1}\left(y(\tau)_{i+1}-y(\tau)_{i}\right)^{2}$,

where $\tau$ is the integration time, $y(\tau)$ is the average value of the measurements in an integration bin of length $\tau, n$ is the total number of bins, and AVAR is the Allan variance. The idea of integration bins simply refers to taking a long sequence of data and dividing it into smaller successive bins of a certain averaging time $\tau$, and then averaging the values in each bin to determine values for $y(\tau)$.

We determine Allan deviation (the square root of Allan variance) for a continuous flow of isotopically homogenous water into the CRDS-CFA on a daily basis. The Allan deviation values for an $11 \mathrm{~h}$ run are plotted in Fig. 3, and selected Allan deviation values are shown in Table 3. At small $\tau(\sim 3 \mathrm{~s})$, Allan deviation is highest due to instrument measurement noise. At longer $\tau$ ( $\sim 3$ to $1000 \mathrm{~s})$, Allan deviation decreases because the sample is analyzed longer, and the instrument measurement noise will average out. At $\sim 1000 \mathrm{~s}$, a noise floor is reached, and longer $\tau$ does not improve the measurement results. At even longer $\tau$, Allan deviation will again increase due to instrument drift from long-term temperature changes, componentry degradation, or other factors. This increase is not observed in the data, as shown in Fig. 3. The Allan deviation plot we provide extends to $40000 \mathrm{~s}(11 \mathrm{~h})$, and from Fig. 1 a typical analysis day lasts about $50000 \mathrm{~s}(\sim 14 \mathrm{~h})$. Since we measure standards twice per day (morning and evening), the maximum temporal distance between standard measurements and any ice core data point is about $7 \mathrm{~h}$. The Allan deviation plot shows instrument stability up to $11 \mathrm{~h}$, thus demonstrating that isotopic calibrations occur at sufficiently short timescales to account for any possible long-term drift in the system. The Allan deviation results shown here are similar to those shown in Fig. 4 of Gkinis et al. (2010) for a comparable CRDS-CFA system.

Relative to a set flow rate, an increase in integration time decreases the resolution of measured ice core data. Therefore, a choice must be made between the integration time and the amount of smoothing introduced into an ice core record. The Allan deviation tests described above inform these decisions relative to sample input originating at the Valco stream selection valve. In Sect. 3.1, we show that it is important to also use replicate ice sticks to analyze system performance for sample input originating at the melt head.

\subsubsection{Mixing length calculations}

Isotopic mixing effects occur in the CRDS-CFA system. Possible contributors to the mixing effect include liquid mixing in tubing and the debubbler, liquid drag on tubing walls, vapor mixing downstream of the nebulizer, vapor interactions with two Picarro instrument filters (Mykrolis Wafer-
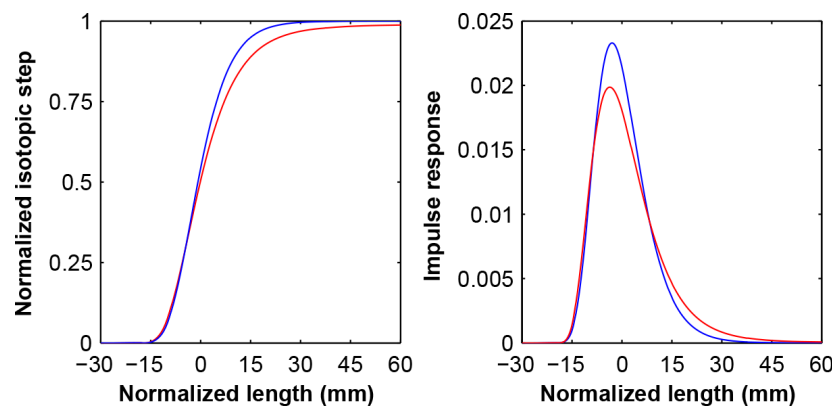

Figure 4. The $\log -\log \mathrm{CDF}$ transfer functions (left) and skewnormal impulse response functions (right) of the CRDS-CFA system for $\delta \mathrm{D}$ (red) and $\delta^{18} \mathrm{O}$ (blue). The normalized functions are fitted to a mock ice isotopic step change in $\delta \mathrm{D}$ of approximately -240 to $-120 \%$. The normalized length scale is calculated using an average melt rate of $2.5 \mathrm{~cm} \mathrm{~min}^{-1}$. Note that the impulse response of $\delta \mathrm{D}$ is slightly wider than for $\delta^{18} \mathrm{O}$, which could possibly arise from diffusional effects in the system, differing interactions of water molecules with the Picarro filters, and differing memory effects within the Picarro cavity.

gard) prior to entering the laser cavity, adsorption of water molecules onto the laser cavity walls, and diffusional effects that can occur at any point in the CRDS-CFA system. To characterize the mixing, a transfer function and impulse response function of the system can be defined using mock ice or laboratory water standards. The transfer function is the system response to an instantaneous isotopic step change at the melt head or Valco stream selection valve. The impulse response function is the first derivative of the transfer function. The standard deviation of the impulse response corresponds to the mixing length (often referred to as diffusion length in other publications), which defines the average movement of a water molecule in the time or depth domain relative to its original position in the ice sample or within a vial of water. Figure 4 shows transfer functions and impulse response functions of the CRDS-CFA system for $\delta \mathrm{D}$ and $\delta^{18} \mathrm{O}$.

In previous work by Gkinis et al. (2010, 2011), a transfer function is fit to an isotopic step change using a scaled version of the cumulative distribution function (CDF) of a normal distribution described by

$\delta_{\text {model }}(t)=\frac{C_{1}{ }^{\prime}}{2}\left[1+\operatorname{erf}\left(\frac{t-t_{o}}{\sigma_{n} \sqrt{2}}\right)\right]+C_{2}{ }^{\prime}$,

where $C_{1}{ }^{\prime}$ and $C_{2}{ }^{\prime}$ are isotopic step-change values, $t$ is the time, $t_{o}$ is the initial time, and $\sigma_{n}$ is the standard deviation (i.e., the mixing length) - all of which are determined by least-squares optimization. The impulse response of the system is described by a Gaussian:

$G_{n}(t)=\frac{1}{\sigma_{n} \sqrt{2 \pi}} e^{-\frac{t^{2}}{2 \sigma_{n}^{2}}}$ 
We modified this approach because the system response to an isotopic step change is skewed (see Fig. 4). We instead fit a transfer function in the form of a lognormal CDF multiplied with a lognormal CDF (log-log fit):

$$
\begin{aligned}
\delta_{\text {model }}(t) & =\frac{1}{2}\left[1+\operatorname{erf}\left(\frac{t-\mu_{1}}{\sigma_{1} \sqrt{2}}\right)\right] \\
& \cdot \frac{1}{2}\left[1+\operatorname{erf}\left(\frac{t-\mu_{2}}{\sigma_{2} \sqrt{2}}\right)\right],
\end{aligned}
$$

where $\mu_{1}, \mu_{2}, \sigma_{1}$, and $\sigma_{2}$ are determined by least-squares optimization. The impulse response function is found by fitting a skew-normal probability density function (PDF; Azzalini and Valle, 1996) to the first derivative of the log-log transfer function:

$\delta_{\text {model }}(t)=2 \phi(t) \Phi(\alpha t)$,

where $\phi(t)$ is the standard normal PDF, $\Phi(t)$ is the standard normal CDF, and $\alpha$ is a shape parameter. The transform $t \rightarrow \frac{t-\varepsilon}{\omega}$ introduces the location parameter $\varepsilon$ and the scale parameter $\omega$. The mixing length term $\sigma_{s}$ is then recovered by

$$
\begin{aligned}
\beta & =\frac{\alpha}{\sqrt{1+\alpha^{2}}}, \\
\sigma_{s}^{2} & =\omega^{2}\left(1-\frac{2 \beta^{2}}{\pi}\right),
\end{aligned}
$$

where $\alpha, \varepsilon$, and $\omega$ are estimated by least-squares optimization.

Since mixing effects in the system may stem from potentially different processes occurring in liquid and vapor phases of the CRDS-CFA system, we attempted to separate the portion of the system where vapor dominates. We evaluated mixing effects for the whole system (liquid + vapor) by evaluating mixing lengths determined from step changes in mock ice ( $\left.\sigma_{\text {mock ice }}\right)$. This includes mixing in the melt head, tubing, debubbler, nebulizer, Pyrex furnace tube, and laser cavity. Similarly, mixing lengths were determined from step changes in liquid laboratory isotopic standards $\left(\sigma_{\mathrm{LS}}\right)$ introduced at the Valco valve. The process downstream of this valve is dominated by the vapor phase, with a short $10 \mathrm{~cm}$ section of tubing where liquid water is transported from the Valco to the nebulizer.

Using Eqs. (5)-(10), mixing length values were deter-

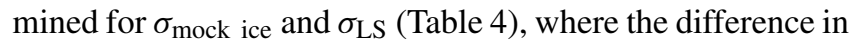
quadrature between the two is the amount of mixing occurring in the liquid phase ( $\left.\sigma_{\mathrm{LQD}}\right)$ of the CRDS-CFA system. We find that the majority of the mixing in the CRDS-CFA system occurs in the liquid phase (i.e., downstream of the melt head to the Valco stream selection valve), while the remainder occurs in the vapor phase of the system (i.e., downstream of the Valco stream selection valve to the laser cavity).
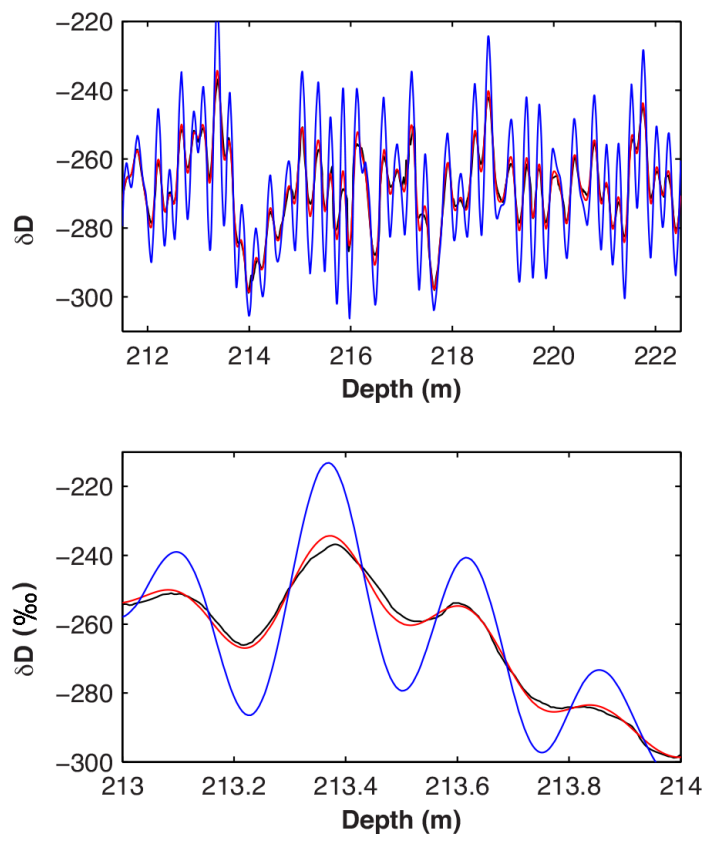

Figure 5. A comparison of the WAIS Divide ice core $\delta \mathrm{D}$ signal measured on the CRDS-CFA system (black); the CRDS-CFA mixing corrected isotopic signal using $\sigma_{\text {mock ice }}$ of $0.8 \mathrm{~cm}$ (red); and a correction for a typical West Antarctic diffusion value of $6.5 \mathrm{~cm}$ (blue), which represents diffusional processes occurring naturally in the ice sheet (see Fig. 6 of Cuffey and Steig, 1998). The mixing introduced by the CRDS-CFA is only a fraction of the diffusion occurring naturally in the ice sheet.

The $\sigma_{\text {mock }}$ ice values are not valid for firn ice, which has much lower densities than deeper ice due to the bubbles and vapor pathways that are present in the firn. The remainder of this paper, except for Sect. 3.3, relates to tests of solid ice beneath the firn column. To illustrate the importance of $\sigma_{\text {mock ice, }}$ consider a series of solid ice core samples that have an average layer thickness of $\sim 23.0 \mathrm{~cm} \mathrm{yr}^{-1}$ (a typical value at $\sim 200 \mathrm{~m}$ depth in the WAIS Divide ice core). A $\sigma_{\text {mock ice }}$ value of $\sim 1 \mathrm{~cm}$ would have almost no effect on the attenuation of the natural signal. However, if the average layer thickness were $\sim 2.0 \mathrm{~cm} \mathrm{yr}^{-1}$ (a typical value for very low accumulation sites in East Antarctica), then $\sigma_{\text {mock ice }}=\sim 1 \mathrm{~cm}$ would have a larger attenuation affect on the isotopic signal. For low-accumulation sites, it may be necessary to adjust the melt rate or decrease the total mixing volume of a CRDS-CFA system so as to decrease the $\sigma_{\text {mock }}$ ice values. Figure 5 shows a comparison of isotopic signal corrections using $\sigma_{\text {mock ice }}$ for the CRDS-CFA system vs. a typical diffusion length occurring naturally from diffusional processes in the Antarctic Ice Sheet at the location of the WAIS Divide ice core. In the data output file, values of $\sigma_{\text {mock ice }}$ and melt rate are included for all depths to allow for CRDS-CFA mixing length corrections (i.e., deconvolution corrections). It is at the discretion of the output file user whether to make these corrections. 
Table 4. Mean mixing length values from 50 determinations of mock ice step changes $\left(\sigma_{\text {mock ice }}\right)$ and for laboratory isotopic standards step changes $\left(\sigma_{\mathrm{LS}}\right)$. The difference in quadrature of $\sigma_{\text {mock ice }}$ and $\sigma_{\mathrm{LS}}$ is the amount of mixing occurring in the liquid phase of the CRDSCFA system $\left(\sigma_{\mathrm{LQD}}\right)$. Mixing length values for both skew and normal impulse response functions are given in seconds and in meters (in parentheses), based on a melt rate of $2.5 \mathrm{~cm} \mathrm{~min}^{-1}$. Values with an asterisk represent $1 \sigma$ variability in meters.

\begin{tabular}{lrr|rr|rr}
\hline & \multicolumn{2}{c|}{$\sigma_{\mathrm{LS}}$} & \multicolumn{2}{|c|}{$\sigma_{\text {mock ice }}$} & \multicolumn{2}{|c}{$\sigma_{\mathrm{LQD}}$} \\
\hline Fit type & $\delta \mathrm{D}$ & $\delta^{18} \mathrm{O}$ & $\delta \mathrm{D}$ & $\delta^{18} \mathrm{O}$ & $\delta \mathrm{D}$ & $\delta^{18} \mathrm{O}$ \\
\hline Skew & 10.3 & 9.6 & 18.7 & 17.7 & 15.6 & 14.9 \\
& $(0.004)$ & $(0.004)$ & $(0.008)$ & $(0.007)$ & $(0.007)$ & $(0.006)$ \\
& $(* 0.0002)$ & $(* 0.0002)$ & $(* 0.0009)$ & $(* 0.0009)$ & & \\
\hline Normal & 10.2 & 9.4 & 19.1 & 17.4 & 16.1 & 14.6 \\
& $(0.004)$ & $(0.004)$ & $(0.008)$ & $(0.007)$ & $(0.007)$ & $(0.006)$ \\
& $(* 0.0002)$ & $(* 0.0002)$ & $(* 0.0008)$ & $(* 0.0009)$ & & \\
\hline
\end{tabular}

Table 5. The average bias and the standard deviation of the mean (\%o) for 50 determinations of isotopic step-change corrections using mock ice (i.e., $\delta \mathrm{D}$ step-change values of approximately -240 to $-120 \%$ ). Each data bin includes 20 consecutive data points (spanning $\sim 17 \mathrm{~s}$ of analysis time), increasing from $c_{n}=0.5$. The data in each bin are averaged for each determination. Corrected values of $\mathrm{dxs}$ are calculated from the corrected $\delta \mathrm{D}$ and $\delta^{18} \mathrm{O}$ values. From $c_{n}=0.5$, about $100 \mathrm{~s}$ is needed to achieve greater than $98 \%$ of the expected mock ice value of $-120 \%$. For comparison, the calculation of the standard deviation of the mean for 50 determinations of $17 \mathrm{~s}$ averages of isotopically homogenous water yields values for $\delta \mathrm{D}, \delta^{x} \mathrm{O}$, and dxs of $0.01,0.01$, and $0.05 \%$, respectively. The isotopically homogenous water was allowed to run through the CRDSCFA system for $1 \mathrm{~h}$ before the $17 \mathrm{~s}$ averages were determined.

\begin{tabular}{lrrr}
\hline Bin & $\delta \mathrm{D}$ & $\delta^{18} \mathrm{O}$ & $\mathrm{dxs}$ \\
\hline $0-17 \mathrm{~s}$ & $-0.36(0.28)$ & $0.14(0.05)$ & $-1.49(0.38)$ \\
$17-34 \mathrm{~s}$ & $-0.06(0.30)$ & $0.06(0.03)$ & $-0.55(0.15)$ \\
$34-51 \mathrm{~s}$ & $-0.15(0.27)$ & $0.01(0.04)$ & $-0.21(0.07)$ \\
$51-68 \mathrm{~s}$ & $-0.17(0.18)$ & $-0.01(0.03)$ & $-0.10(0.06)$ \\
$68-85 \mathrm{~s}$ & $-0.18(0.13)$ & $-0.01(0.02)$ & $-0.09(0.05)$ \\
$85-102 \mathrm{~s}$ & $-0.16(0.10)$ & $-0.01(0.02)$ & $-0.05(0.04)$ \\
\hline
\end{tabular}

\subsubsection{Isotopic step-change correction}

During a typical analysis day, every fourth ice core stick is separated by isotopically distinct push ice. Ideally, the isotopic shift between push ice and the beginning of an ice core stick at the melt head would register instantaneously on the CRDS instrument. However, a substantial mixing effect is evident in the first $\sim 5-7 \mathrm{~cm}$ of an ice core sample. This effect can be partially corrected for by separately determining mixing coefficients $\left(c_{n}\right)$, quantified using an instantaneous shift in mock ice isotopic values at the melt head. The isotopic values of the mock ice sticks are approximately -240 and $-120 \%$. As the water for the mock ice sticks moves through the CRDS-CFA system, the water will mix together, resulting in a smoothed transition over time (rather than an
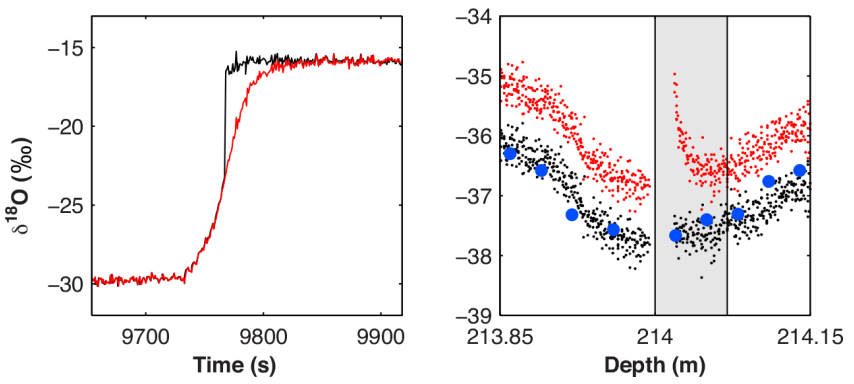

Figure 6. Mixing corrections for mock ice (left) and the beginning of an ice core section (right). The ice core mixing correction is based upon a known step-function change defined by the mock ice, from which mixing coefficients are determined. Red represents raw uncorrected isotopic data with no memory correction, black represents VSMOW corrected data with the memory correction applied, blue dots represent $3 \mathrm{~cm}$ IRMS discrete samples, and the grey region represents the depth range of corrected data that would otherwise be discarded. Note that the time variable represents the amount of run time on a given day.

instantaneous transition) as measured by the CRDS instrument. For example, at a time of $5 \mathrm{~s}$ after a shift in mock ice at the melt head (not including the delay in transport from the melt head to the CRDS instrument), the measured isotopic value may only be $2 \%$ of the expected value. After $40 \mathrm{~s}$ the measured value may be $40 \%$ of the expected value, and after $100 \mathrm{~s}$, the measured value may be $95 \%$ of the expected value. For these three examples, the $c_{n}$ coefficients would be 0.02 , 0.40 , and 0.95 , respectively. To remove noise from the $c_{n}$ calculation, we average mock ice isotopic values, normalize between 0 and 1 , and apply a cubic spline. The water isotope step-change correction is described by Eq. (4) of Vaughn et al. (1998):

$$
\delta_{\mathrm{mc}}=\frac{\delta_{\mathrm{m}}-\delta_{\mathrm{mp}}\left(1-c_{n}\right)}{c_{n}} \text {, }
$$


where $\delta_{\mathrm{m}}$ is the measured isotopic value at index $n, \delta_{\mathrm{mp}}$ is the previously measured isotopic value at $n-1, c_{n}$ is the memory coefficient at $n$, and $\delta_{\mathrm{mc}}$ is the corrected isotopic value at $n$. An example of an isotopic step-change correction, applied to an isotopic shift between push ice and the beginning of an ice core stick, is shown in Fig. 6. For $c_{n} \geq 0.65$, the correction saves an additional $\sim 2.25-3.15 \mathrm{~cm}$ of data that would otherwise be discarded. For a typical deep ice core of $3000 \mathrm{~m}$, there are 750 step changes (every fourth ice core stick). This correction saves $\sim 16.9-23.7 \mathrm{~m}$ of isotopic data. In the data output file we produce, the depths of isotopic step-change corrections are flagged so researchers can decide whether to include some or all of these data in their calculations. In Table 5, we provide standard error estimates for isotopic stepchange corrections of mock ice sticks for different bins of data at $c_{n} \geq 0.5$.

\section{Ice core measurement results}

\subsection{Greenland test ice}

To test CRDS-CFA precision for the entire system, nine sticks of solid ice were cut from a single meter of Greenland test ice (GTI) at about $400 \mathrm{~m}$ depth. The ice sticks were obtained from the National Science Foundation National Ice Core Laboratory (Lakewood, Colorado) and were a by-product of the initial tests of the US Deep Ice Sheet Coring Drill performed in Greenland in 2006 (Johnson et al., 2007). The same drill was deployed in West Antarctica to obtain the WAIS Divide ice core, which we discuss in Sect. 3.2. Seven of the nine GTI sticks were analyzed on the CRDSCFA system, three of which were broken into parts to test depth registration methodology. As stated previously, these ice sticks are melted at a rate of $2.5 \mathrm{~cm} \mathrm{~min}^{-1}$, and data are recorded on the CRDS instrument at $0.85 \mathrm{~s}$ intervals. The final two GTI sticks were discretely sampled at 1 and $5 \mathrm{~cm}$ increments, melted into vials, and analyzed on a separate Picarro L2130-i.

The isotopic data for the seven $1 \mathrm{~m}$ long GTI sticks analyzed on the CRDS-CFA system were measured at submillimeter resolution. These data were then averaged to $1 \mathrm{~cm}$ successive values $(\mathrm{GTI}-1 \mathrm{~cm})$ for each stick, resulting in seven values at each $1 \mathrm{~cm}$ increment, from which a standard deviation was determined. This resulted in a total of 100 standard deviation values, and the mean of these values is used to estimate the full-system precision (Fig. 7). We find full-system precision values $(1 \sigma)$ for $\delta \mathrm{D}, \delta^{18} \mathrm{O}$, and dxs of $0.55,0.09$, and $0.55 \%$, respectively. For comparison, traditional IRMS measurements using uranium reduction for $\delta \mathrm{D}$ and $\mathrm{CO}_{2}-\mathrm{H}_{2} \mathrm{O}$ equilibration for $\delta^{18} \mathrm{O}$ are commonly reported with a precision of about 1.0 and $0.1 \%$, respectively. The resulting dxs precision using these two measurement techniques is about $1.3 \%$.
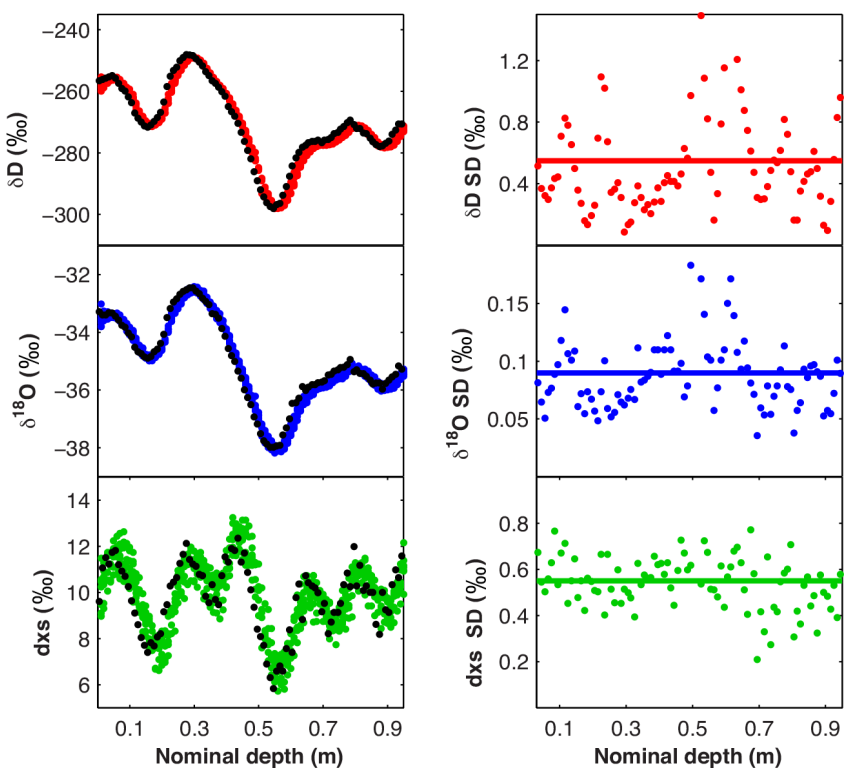

Figure 7. Greenland test ice (GTI) for a nominal $1 \mathrm{~m}$ section. In the left column, seven GTI sticks measured on the CRDS-CFA system averaged to $1 \mathrm{~cm}$ increments for $\delta \mathrm{D}$ (red dots), $\delta^{18} \mathrm{O}$ (blue dots), and $\mathrm{dxs}$ (green dots) compared with discrete $1 \mathrm{~cm}$ samples (black dots) measured on a Picarro L2130-I using the average of three injections. In the right column, the standard deviation of seven GTI values is taken at each $1 \mathrm{~cm}$ increment (red, blue, and green dots). The average standard deviation is shown by the horizontal line, which represents the full-system precision $(1 \sigma)$ for $\delta \mathrm{D}, \delta^{18} \mathrm{O}$, and dxs.

The full-system precision can be subdivided into two parts: noise added to the isotopic signal on the preparation side of the system (i.e., noise occurring prior to the Valco stream selection valve, including depth registration) and noise added to the isotopic signal on the vapor side of the system (i.e., noise occurring downstream of the Valco stream selection valve, including the nebulizer and CRDS laser cavity). We define noise as a disturbance that obscures or reduces the clarity of the original water isotope signal in the ice core. We can isolate the noise added on the vapor side of the system by analyzing a continuous stream of IHW inputted directly into the nebulizer from the Valco valve and subsequently analyzed on the CRDS instrument. We take averages of the IHW over consecutive $24 \mathrm{~s}$ intervals, which correspond to the time needed to melt $1 \mathrm{~cm}$ of ice at a melt rate of $2.5 \mathrm{~cm} \mathrm{~min}^{-1}$. The standard deviation of 100 consecutive $24 \mathrm{~s}$ averages of the IHW (the equivalent of a meter-long section of ice) yields an IHW precision value, which is an estimate of the noise added to the isotopic signal on the vapor side of the system (similar to that determined in Sect. 2.4.2). The difference in quadrature of this IHW precision value and the full-system precision value (determined from GTI) gives an estimate of the noise added to the isotopic signal on the preparation side of the system upstream of the Valco valve (Table 6). We find that the added preparation side noise is 

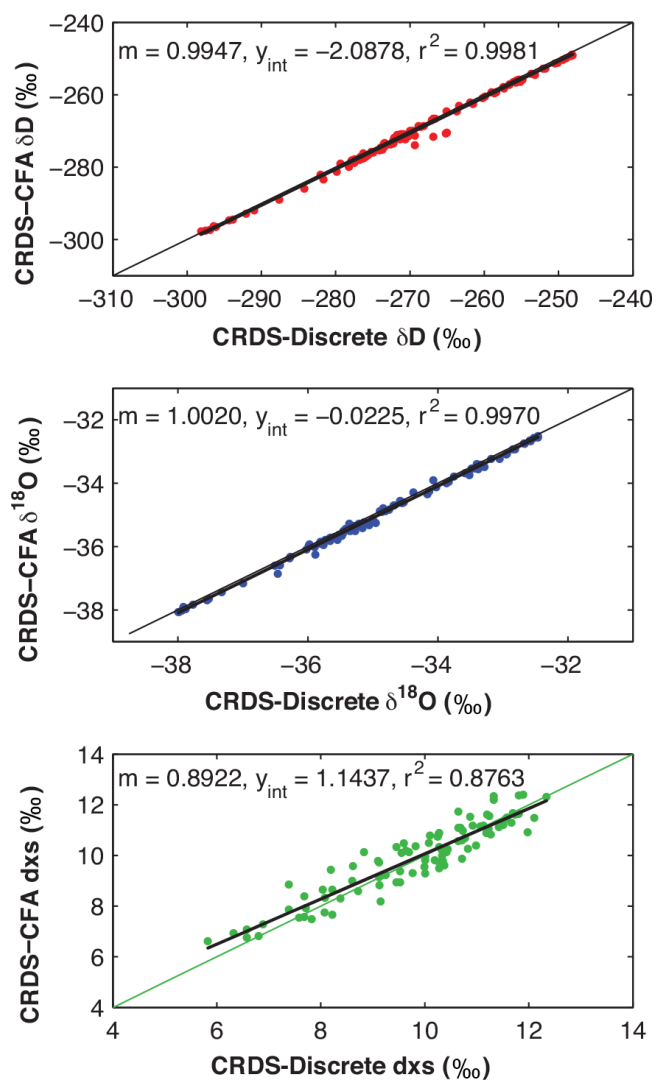

Figure 8. Scatterplots of GTI comparisons of CRDS-CFA vs. CRDS-discrete data. Seven GTI sticks were analyzed on the CRDSCFA system, down-sampled to $1 \mathrm{~cm}$, and averaged. The discrete data were sampled at $1 \mathrm{~cm}$ and analyzed on a separate Picarro L2130i using the average of three injections. The black line is the best-fit linear regression. The $1 \sigma$ errors for the slope and intercept of the $\delta \mathrm{D}$ regression are 0.0035 and 0.9346 , respectively. For the $\delta^{18} \mathrm{O}$ regression, the errors are 0.0045 and 0.1555 , respectively. For the $\mathrm{dxs}$ regression, the errors are 0.0315 and 0.3116 , respectively.

significantly larger than the noise added on the vapor side of the system.

As a final analysis using GTI, the reproducibility of GTI$1 \mathrm{~cm}$ CRDS-CFA data and $1 \mathrm{~cm}$ discrete CRDS data is compared. We define reproducibility as the closeness of the agreement between results of measurements of the same measure and carried out under changed conditions of measurement. In this case, the same water samples are analyzed using a Picarro L2130-i, but the exact conditions of measurement are different, in that some samples are analyzed on the CFA-CRDS system, while others are analyzed by discrete sample injection into a CRDS instrument. A scatterplot and linear regression of the resulting data for the two measurement types give a slope, $y$ intercept, and $R^{2}$ value (Fig. 8). The coefficient of determination values $\left(R^{2}\right)$ for $\delta \mathrm{D}$ and $\delta^{18} \mathrm{O}$ are 0.9981 and 0.9970 , respectively, while dxs remains inherently more difficult to measure with an $R^{2}$ value of 0.8763 . Because this test shows the comparison of seven GTI sticks

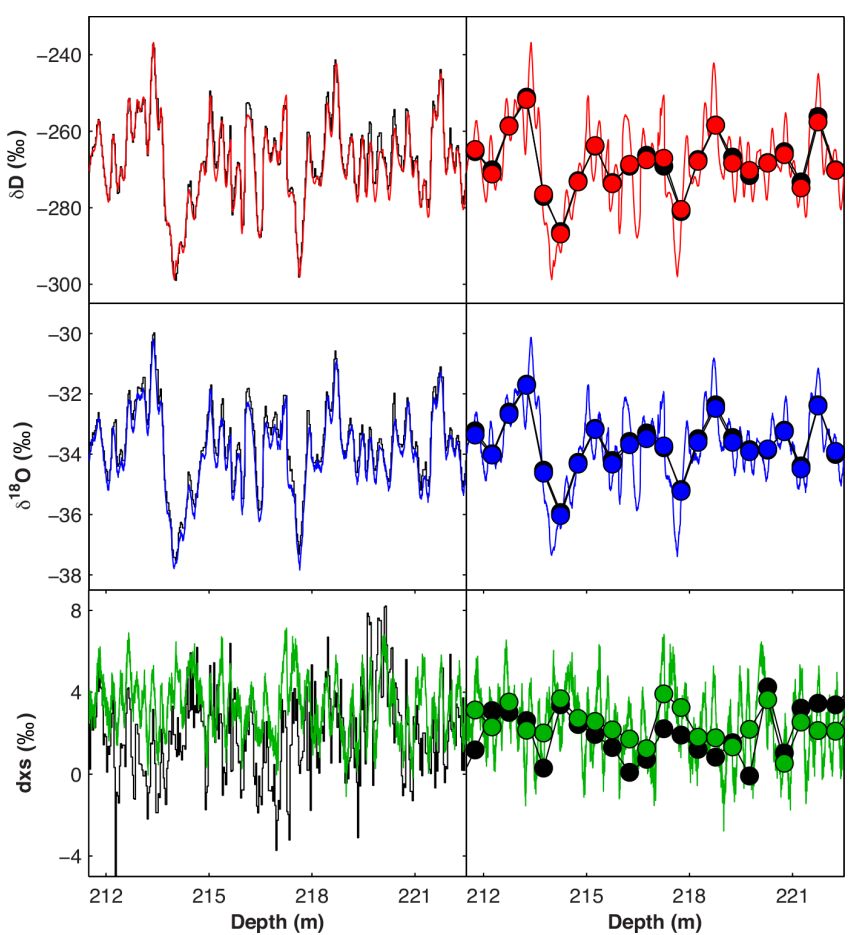

Figure 9. Data from the WDC over a depth range of $\sim 212-222 \mathrm{~m}$. In the left column, high-resolution CRDS-CFA data for $\delta \mathrm{D}$ (red line), $\delta^{18} \mathrm{O}$ (blue line), and $\mathrm{dxs}$ (green line) are compared with traditional high-resolution IRMS discrete samples (black lines). In the right column, comparison of high-resolution CRDS-CFA data (red, blue, and green lines), low-resolution University of Washington CRDS discrete samples (black dots), and down-sampled CRDSCFA data (red, blue, and green dots).

analyzed on CRDS-CFA compared with a single ice stick measured discretely on CRDS, the $R^{2}$ values represent the reproducibility of the average of seven ice sticks vs. a single ice stick carried out under changed conditions of measurement. We explore the reproducibility of sets of single ice sticks for IRMS and CRDS in the following section.

\subsection{WAIS Divide ice core tests}

The reproducibility of traditional IRMS discrete measurements and CRDS-CFA measurements (both analyzed at the INSTAAR SIL) was tested on the WAIS WDC over depths of $\sim 212-222 \mathrm{~m}$ (Fig. 9). The discrete samples ( $3 \mathrm{~cm}$ cuts) were measured using a uranium reduction technique for $\delta \mathrm{D}$ (Vaughn et al., 1998) and a $\mathrm{CO}_{2}-\mathrm{H}_{2} \mathrm{O}$ equilibration method for $\delta^{18} \mathrm{O}$ (Epstein, 1953; Craig et al., 1963). We find that the amplitude of the $\delta$ signal between the IRMS and CRDS-CFA techniques is nearly identical, albeit with an occasional offset in $\delta \mathrm{D}$ of $3-4 \%$ and $\delta^{18} \mathrm{O}$ of $0.4-0.5 \%$. The offsets in $\delta \mathrm{D}$ and $\delta^{18} \mathrm{O}$ do not always occur over the same interval of ice. One possibility is that the standard water calibration on the IRMS instruments was offset relative to the CRDS for some sample groups, which would account for the occasional offset in 
Table 6. The isotopic measurement precision $(1 \sigma)$ of varying parts of the CRDS-CFA system (\%o). The difference in quadrature of the full-system precision derived from GTI (system) and the precision derived from IHW (vapor-side) gives an estimate of the noise added on the preparation side of the system (prep-side). The prep-side values include noise added to the isotopic signal upstream of the Valco valve, while the vapor-side values include noise added to the isotopic signal downstream of the Valco valve.

\begin{tabular}{lrrr}
\hline Measurement & System & Vapor-side & Prep-side \\
\hline$\delta \mathrm{D}$ & 0.55 & 0.09 & 0.54 \\
$\delta^{18} \mathrm{O}$ & 0.09 & 0.04 & 0.08 \\
$\mathrm{dxs}$ & 0.55 & 0.32 & 0.45 \\
\hline
\end{tabular}

$\delta \mathrm{D}$ and $\delta^{18} \mathrm{O}$ values while retaining the same signal amplitude. Furthermore, if the calibrations for $\delta \mathrm{D}$ and $\delta^{18} \mathrm{O}$ were offset in different intervals of ice, this could possibly cause the IRMS dxs values to be negative. Indeed, the dxs values in the IRMS samples are decreased and more negative over the $10 \mathrm{~m}$ section as compared to CRDS-CFA, sometimes with offsets of up to $7 \%$. Another possible explanation for negative IRMS dxs values is that there was fractionation within some of the discrete sample vials over time.

A second WDC reproducibility test was performed between high-resolution CRDS-CFA measurements and lowresolution discrete CRDS measurements (Fig. 9). The lowresolution data were measured at the University of Washington (UW) using a Picarro $2120 \mathrm{i}$ at $\sim 50 \mathrm{~cm}$ increments (Steig et al., 2013). To determine inter-lab reproducibility, we averaged the high-resolution CRDS-CFA data to the exact low-resolution discrete CRDS increments; we refer to this as "down-sampling". Over a depth of 212-222 m, scatterplot comparisons of the down-sampled high-resolution data and low-resolution measurements have $R^{2}$ values for $\delta \mathrm{D}, \delta^{18} \mathrm{O}$, and dxs of $0.9871,0.9944$, and 0.2885 , respectively. The slopes are $1.0113,0.9928$, and 0.7658 , respectively, and the $1 \sigma$ errors for the slopes are $0.0175,0.0065$, and 0.1960 , respectively. The $y$ intercepts are $3.2457,-0.1730$, and 0.4152 , respectively, and the $1 \sigma$ errors for the $y$ intercepts are 4.6688 , 0.2235 , and 0.6750 , respectively.

The combination of WDC test results leads to the following conclusions: (1) the $\delta \mathrm{D}$ and $\delta^{18} \mathrm{O}$ data are reproducible between traditional IRMS and CRDS-CFA techniques (both measured at INSTAAR), albeit with an occasional offset in magnitude but not amplitude. We suggest, but cannot prove, that the offset is due to standard water calibration difficulties using IRMS, or due to outdated sample storage techniques that introduced additional fractionation in the IRMS samples. (2) The dxs data between IRMS and CRDS-CFA (both measured at INSTAAR) are not reproduced well, possibly due to the uncertainty introduced by multi-system IRMS measurements or because the discrete samples underwent additional fractionation due to storage procedures. (3) However, the CRDS-CFA analysis of GTI (measured at INSTAAR) shows
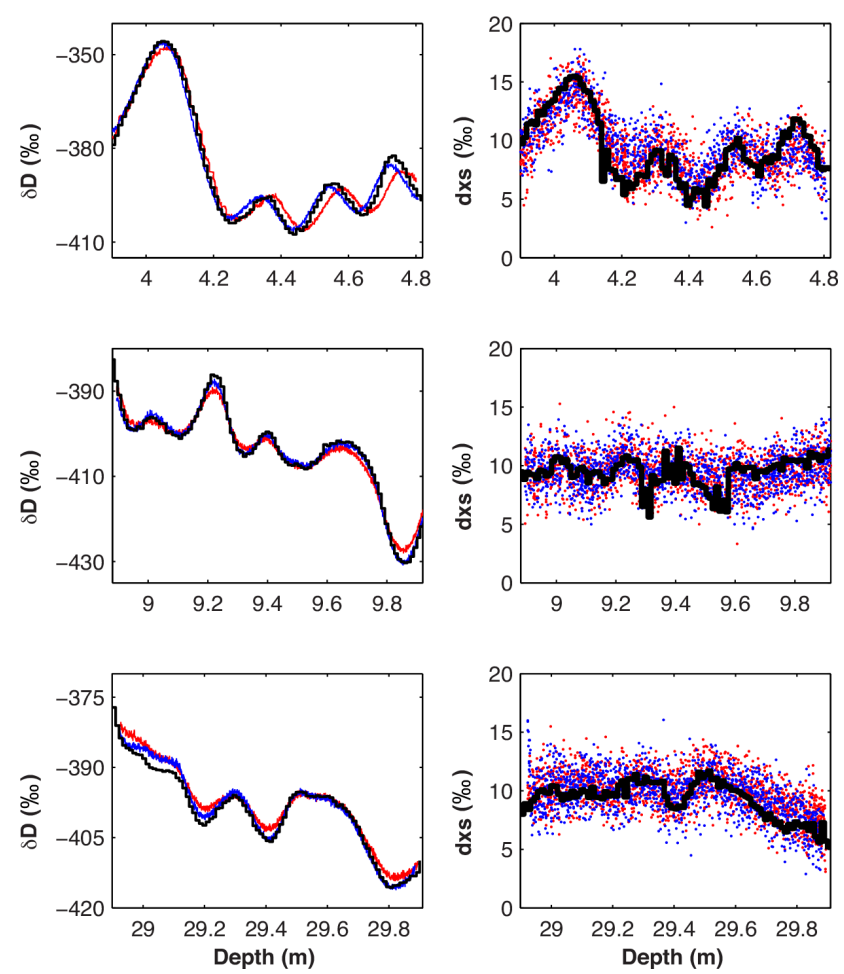

Figure 10. Replicate SPF ice measurements of $\delta \mathrm{D}$ and dxs at depths of $\sim 4,9$, and $29 \mathrm{~m}$, corresponding to densities of 340,386 , and $562 \mathrm{~kg} \mathrm{~m}^{-3}$, respectively. The red and blue data are from SPF sticks analyzed on the CRDS-CFA system, and the black data are $1 \mathrm{~cm}$ discrete samples analyzed on a separate Picarro L2130-i.

that the full-system precision of dxs has a low average standard deviation of $0.55 \%$ and, when compared with discrete CRDS samples, has a high $R^{2}$ value of 0.88 . This shows that the INSTAAR CRDS-CFA is capable of reliably measuring $\mathrm{dxs}$ at high frequencies (annual to multi-year). (4) Yet interlab reproducibility (INSTAAR CRDS-CFA vs. UW CRDS) of down-sampled dxs has a low $R^{2}$ value of 0.29 , but still within the same range of values between $\sim 1$ and $4 \%$. These results suggest that the inherent noise in dxs measurements may make this parameter most useful at timescales of centuries to millennia when the range of WDC dxs increases to $\sim 0$ to $12 \%$ o (Markle et al., 2017).

\subsection{South Pole firn tests}

Until this point, the analyses in this paper have focused on solid ice; we now shift focus to firn ice, which involves additional complexities. Due to the increased porosity and lower density of firn ice, liquid water at the melt head can wick upwards by capillary action through the pore spaces, artificially smoothing the isotopic signal and decreasing signal amplitude. This can, for example, alter frequency analysis calculations or cause the misinterpretation of the size of summerwinter signals. The melt rate is also difficult to control, as density variations over a few centimeters can cause the melt 
rate to increase or decrease unexpectedly. Furthermore, we have not devised a reliable way to test $\sigma_{\text {mock ice }}$ for firn, as the interconnected vapor pathways and trapped air bubbles are difficult to replicate in the lab. For this reason, we can only test the reliability of CRDS-CFA firn measurements by comparing the CFA measurements to discrete samples over the same intervals of ice. To test the repeatability of CRDSCFA firn measurements, two identical $1 \mathrm{~m}$ sections from 4, 9, and $29 \mathrm{~m}$ depth in a South Pole firn core are analyzed under the same conditions of measurement (hereafter referred to as South Pole firn: SPF). These CRDS-CFA firn measurements are then compared with a third identical $1 \mathrm{~m}$ SPF section discretely sampled at $1 \mathrm{~cm}$ increments using a Picarro L2130-i (Fig. 10).

Based upon a steady-state Herron and Langway density model (Herron and Langway, 1980), the SPF sticks have estimated densities of 340,386 , and $562 \mathrm{~kg} \mathrm{~m}^{-3}$ at depths of 4,9 , and $29 \mathrm{~m}$, respectively (assuming an average accumulation rate of $0.085 \mathrm{~m} \mathrm{yr}^{-1}$, average temperature of $-50^{\circ} \mathrm{C}$, average snow density in the top $2 \mathrm{~m}$ of $300 \mathrm{~kg} \mathrm{~m}^{-3}$, and pore close-off density of $804.3 \mathrm{~kg} \mathrm{~m}^{-3}$ ). For comparison, the density of snow at the surface of the WAIS Divide ice core is $\sim 370 \mathrm{~kg} \mathrm{~m}^{-3}$. Because of the low-density SPF sticks, the melt rate was increased from 2.5 to $4.4 \mathrm{~cm} \mathrm{~min}^{-1}$ to prevent wicking during this experiment. We observed that no wicking occurred during the melting process.

The data show that a loss in $\delta \mathrm{D}$ amplitude not surpassing $11 \%$ occurred in the CRDS-CFA data relative to the discretely sampled data, while maximum depth registration offsets were $4,<0.5$, and $<0.5 \mathrm{~cm}$ at 4,9 , and $29 \mathrm{~m}$ depth, respectively. At $4 \mathrm{~m}$ depth, the phase of the CRDS-CFA and discrete $\delta \mathrm{D}$ signal is offset by about $3 \mathrm{~cm}$ over the last $\sim 60 \mathrm{~cm}$ of the SPF section, which is likely related to imprecise depth registration on the CRDS-CFA due to the increased melt rate, fluctuations in the melt rate, or unobserved wicking. At $29 \mathrm{~m}$ depth, CRDS-CFA $\delta \mathrm{D}$ measurements are anomalously higher than discrete measurements in the first $20 \mathrm{~cm}$. The dxs values for the CRDS-CFA and $1 \mathrm{~cm}$ discrete signals have the same pattern and range of values, except for small offsets in the last $\sim 60 \mathrm{~cm}$ of the $4 \mathrm{~m}$ depth section and again at $\sim 9.30$ and $\sim 9.55 \mathrm{~m}$. We note that the ability to analyze the SPF samples was likely improved due to long storage times that allowed the ice sticks to sinter, increasing the structural integrity of the samples. We have found in other subsequent experiments that short storage times cause lowdensity firn sticks to collapse when placed vertically in the CFA system, introducing large uncertainty in depth registration and essentially unusable isotopic data.

\subsection{Method comparison}

The CRDS-CFA setup presented in this paper (INSTAAR; CRDS L-2130i) can be compared with similar studies from Victoria University of Wellington (VUW; OA-ICOS "custom 2014 setup") and the University of Copenhagen (UC; CRDS
L-2140i; Emanuelsson et al., 2015), as well as the Desert Research Institute (DRI; CRDS L-2120i and L-2130i; Maselli et al., 2012). Allan deviation values of $\delta \mathrm{D}$ at $10^{3} \mathrm{~s}$ for INSTAAR, VUW, UC, DRI-2120i, and DRI-2130i are 0.020, $0.060,0.048, \sim 0.15$, and $\sim 0.20 \%$ o, respectively. For $\delta^{18} \mathrm{O}$, these values are $0.010,0.030,0.011, \sim 0.06$, and $\sim 0.02 \%$, respectively. Allan deviation values of $\delta \mathrm{D}$ at $10^{4} \mathrm{~s}$ for INSTAAR, VUW, and UC are 0.013, $\sim 0.04$, and $\sim 0.11 \%$, respectively. For $\delta^{18} \mathrm{O}$, these values are $0.008, \sim 0.06$, and $\sim 0.006 \%$, respectively. No Allan deviation values at $10^{4} \mathrm{~s}$ are given for DRI. Mixing length values of ice introduced at the melt head for INSTAAR ( $\delta \mathrm{D}$ isotopic step change of $120 \%$ ) and both DRI instruments (step-change amount not clearly given) are 19.1 and $\sim 24 \mathrm{~s}$, respectively. For the equivalent $\delta^{18} \mathrm{O}$ step change, these values are 17.4 and $\sim 24 \mathrm{~s}$. Note that the DRI study did not differentiate between $\delta \mathrm{D}$ and $\delta^{18} \mathrm{O}$ for mixing lengths. Mixing length values of ice introduced at the selector valve for INSTAAR $(\delta \mathrm{D}$ isotopic step change of $120 \%$ o), VUW (step change of $124 \%$ ), UC (step change of $253 \%$ ), and both DRI instruments (stepchange amount not clearly given) are 10.2, 18.5, 93.6, and $17 \mathrm{~s}$, respectively. For the equivalent $\delta^{18} \mathrm{O}$ step change, these values are 9.4, 18.4, 90.3, and $17 \mathrm{~s}$, respectively. Specific selector valve placements and total mixing volume can be referenced in each manuscript's system schematic.

The important difference between this study and prior studies is that we perform tests of replicate ice sticks originating at the melt head, rather than testing Allan deviation of sample input originating at the selector valve. This is an important distinction, as there are factors that affect the isotopic data prior to the selector valve, such as depth registration and mixing in the debubbler.

\section{Conclusions}

We have presented a high-resolution CFA system based on CRDS technology that is specifically designed for water isotope analysis of ice cores. The CFA system converts $\sim 1 \mathrm{~m}$ ice sticks into a continuous liquid water stream, which is then vaporized and analyzed on a CRDS instrument. The full system builds from previous water isotope CFA studies (Gkinis et al., 2010, 2011; Maselli et al., 2013; Emanuelsson et al., 2015) and includes novel improvements to the ice delivery mechanism and the melt head. In terms of Allan deviation and response time, the CRDS-CFA system presented here performed similarly to previously published systems from the US, New Zealand, and Denmark (Gkinis et al., 2010, 2011; Maselli et al., 2013; Emanuelsson et al., 2015).

We have tested two types of ice cores on the CRDS-CFA system: firn ice and solid ice beneath the bubble close-off depth in the firn. Using South Pole firn samples, we find that the CRDS-CFA measurements are not of high-enough quality for most scientific analyses, due mainly to difficulties in controlling the melt rate with low-density firn ice. We sug- 
gest that researchers instead utilize high-resolution discrete samples for firn column measurements. For solid ice, we used seven identical Greenland ice core sticks to quantify the precision of the CRDS-CFA system. This technique is previously unpublished and helps quantify as many sources of uncertainty on the CRDS-CFA system as possible, including depth registration and sample mixing. Additionally, we measured West Antarctic ice core sticks to test the reproducibility of two sets of measurements: (1) traditional magnetic sector IRMS vs. CRDS-CFA system measurements, and (2) interlab comparisons of CFA and discrete measurements on the same type of CRDS instrument. We find that the CRDS-CFA system provides a $\sim 6$-fold time savings and an order-ofmagnitude improvement in data density compared to traditional IRMS methods. Inter-lab comparisons of $\delta \mathrm{D}$ and $\delta^{18} \mathrm{O}$ were strongly correlated $\left(R^{2}\right.$ values of 0.9871 and 0.9944 , respectively).

One exception to these solid ice results is found in the dxs measurements. At the highest frequencies (multi-year to decadal), we found discrepancies in comparisons of both inter-lab CRDS measurements of dxs and in CRDS and IRMS measurements of dxs. Contrary to this, however, are the dxs results measured solely on the CRDS-CFA system presented in this paper. We found that dxs can be replicated at high frequencies, demonstrated by tests of identical Greenland ice core sticks. Furthermore, despite slightly different impulse response functions for $\delta \mathrm{D}$ and $\delta^{18} \mathrm{O}$, the dxs measured from replicate ice sticks on the CRDS-CFA system is strongly correlated $\left(R^{2}=0.88\right)$ with discrete CRDS dxs values measured on the same replicate ice. This indicates a negligible artifact in dxs calculations arising from the differing impulse response functions. To better understand highresolution measurements of dxs, we suggest additional multilab studies be undertaken.

The overall results are in line with prior ice core CFA studies. Gkinis et al. (2011) cite combined measurement uncertainty values of $0.2,0.06$, and $0.5 \%$ for $\delta \mathrm{D}, \delta^{18} \mathrm{O}$, and dxs, respectively. Maselli et al. (2013) and Emanuelsson et al. (2015) report similar results. However, unlike these prior studies, the precision values cited in this paper $(0.55,0.09$, and $0.55 \%$, respectively) were determined using seven replicate ice core sticks and therefore cannot be compared directly. We suggest that future CFA studies include determinations of precision using replicate ice sticks, as this is most representative of the variations introduced into water isotope measurements downstream of the ice core melt head. In addition, Allan deviation comparisons should be made, but this only takes into consideration the sample flow downstream of the selector valve, rather than downstream of the melt head. Similarly, total mixing length values can be measured downstream of the melt head and downstream of the selector valve, yielding insights into system behavior. We find the majority of mixing occurs between the melt head and selector valve.

\section{Data availability}

The high-resolution WDC Water Isotope Data can be found at http://gcmd.gsfc.nasa.gov/search/Metadata.do?entry= NSF-ANT10-43167.

The low-resolution WDC Water Isotope Data can be found at http://gcmd.gsfc.nasa.gov/search/Metadata.do? entry=WAIS_Divide_Isotope_Data.

Additional data inquiries can be made to the corresponding author, Tyler R. Jones (tyler.jones@ colorado.edu).

Competing interests. The authors declare that they have no conflict of interest.

Acknowledgements. This work was supported by US National Science Foundation (NSF) grants 0537930, 0537593, 1043092, and 1043167. The authors would like to thank all field crew, laboratory staff, students, and principal investigators involved with the project. Field and logistical activities were managed by the WAIS Divide Science Coordination Office at the Desert Research Institute, Reno, NE, USA, and the University of New Hampshire, USA (NSF grants 0230396, 0440817, 0944266, and 0944348). The National Science Foundation Division of Polar Programs funded the Ice Drilling Program Office (IDPO), the Ice Drilling Design and Operations (IDDO) group, the National Ice Core Laboratory (NICL), the Antarctic Support Contractor, and the 109th New York Air National Guard. Finally, we would like to thank the Centre for Ice and Climate at the Niels Bohr Institute, University of Copenhagen, for support in the design of the analysis system used in this study.

Edited by: R. Koppmann

Reviewed by: J. Rudolph and one anonymous referee

\section{References}

Allan, D. W.: Statistics of atomic frequency standards, P. IEEE, 54, 221-230, 1966.

Alley, R. B.: Ice-core evidence of abrupt climate changes, P. Natl. Acad. Sci. USA, 97, 1331-1334, 2000.

Azzalini, A. and Dalla Valle, A.: The multivariate skew-normal distribution, Biometrika, 83, 715-726, 1996.

Bigeleisen, J., Perlman, M. L., and Prosser, H. C.: Conversion of hydrogenic materials to hydrogen for isotopic analysis, Anal. Chem., 24, 1356-1357, 1952.

Bigler, M., Svensson, A., Kettner, E., Vallelonga, P., Nielsen, M. E., and Steffensen, J. P.: Optimization of high-resolution continuous flow analysis for transient climate signals in ice cores, Environ. Sci. Technol., 45, 4483-4489, 2011.

Bond, G. C.: Catalysis by metals, Annu. Rep. Prog. Chem. A, 65, 121-128, 1968.

Brand, W. A., Geilmann, H., Crosson, E. R., and Rella, C. W.: Cavity ring-down spectroscopy versus high-temperature conversion isotope ratio mass spectrometry, a case study on $\delta^{2} \mathrm{H}$ and $\delta^{18} \mathrm{O}$ of 
pure water samples and alcohol/water mixtures, Rapid Commun. Mass Sp., 23, 1879-1884, 2009.

Coleman, M. L., Shepherd, T. J., Durham, J. J., Rouse, J. E., and Moore, G. R.: Reduction of water with zinc for hydrogen isotope analysis, Anal. Chem., 54, 993-995, 1982.

Coplen, T. B., Wildman, J. D., and Chen, J.: Improvements in the gaseous hydrogen-water equilibration technique for hydrogen isotope-ratio analysis, Anal. Chem., 63, 910-912, 1991.

Craig, H., Gordon, L. I., and Horibe, Y.: Isotopic exchange effects in the evaporation of water: 1. Low-temperature experimental results, J. Geophys. Res., 68, 5079-5087, 1963.

Crosson, E. R.: A cavity ring-down analyzer for measuring atmospheric levels of methane, carbon dioxide, and water vapor, Appl. Phys. B, 92, 403-408, 2008.

Cuffey, K. M. and Steig, E. J.: Isotopic diffusion in polar firn: implications for interpretation of seasonal climate parameters in icecore records, with emphasis on central Greenland, J. Glaciol., 44, 273-284, 1998.

Dansgaard, W.: Stable isotopes in precipitation, Tellus, 16, 436468, 1964

Dansgaard, W., White, J. W. C., and Johnsen, S. J.: The abrupt termination of the Younger Dryas climate event, Nature, 339, 532534, 1989.

Dansgaard, W.: Frozen Annals - Greenland Icecap Research, Niels Bohr Institute, Narayana Press, Odder, Denmark, available at: www.narayanapress.dk (last access: 1 April 2016), ISBN: 87990078-0-0, 124 pp., 2005.

Emanuelsson, B. D., Baisden, W. T., Bertler, N. A. N., Keller, E. D., and Gkinis, V.: High-resolution continuous-flow analysis setup for water isotopic measurement from ice cores using laser spectroscopy, Atmos. Meas. Tech., 8, 2869-2883, doi:10.5194/amt8-2869-2015, 2015.

Epstein, S., Buchsbaum, R., Lowenstam, H. A., and Urey, H. C.: Revised carbonate-water isotopic temperature scale, Geol. Soc. Am. Bull., 64, 1315-1326, 1953.

Gkinis, V., Popp, T. J., Johnsen, S. J., and Blunier, T.: A continuous stream flash evaporator for the calibration of an IR cavity ring-down spectrometer for the isotopic analysis of water, Isot. Environ. Healt. S., 46, 463-475, 2010.

Gkinis, V., Popp, T. J., Blunier, T., Bigler, M., Schüpbach, S., Kettner, E., and Johnsen, S. J.: Water isotopic ratios from a continuously melted ice core sample, Atmos. Meas. Tech., 4, 25312542, doi:10.5194/amt-4-2531-2011, 2011.

Grootes, P. M., Stuiver, M., White, J. W. C., Johnsen, S., and Jouzel, J.: Comparison of oxygen isotope records from the GISP2 and GRIP Greenland ice cores, Nature, 366, 552-554, 1993.

Gupta, P., Noone, D., Galewsky, J., Sweeney, C., and Vaughn, B. H.: Demonstration of high-precision continuous measurements of water vapor isotopologues in laboratory and remote field deployments using wavelength-scanned cavity ring-down spectroscopy (WS-CRDS) technology, Rapid Commun. Mass Sp., 23, 25342542, 2009.

Herron, M. M. and Langway Jr, C. C.: Firn densification: an empirical model, J. Glaciol., 25, 373-385, 1980.

Huber, C. and Leuenberger, M.: Fast high-precision on-line determination of hydrogen isotope ratios of water or ice by continuous-flow isotope ratio mass spectrometry, Rapid Commun. Mass Sp., 17, 1319-1325, 2003.
Huber, C. and Leuenberger, M.: On-line systems for continuous water and gas isotope ratio measurements, Isot. Environ. Healt. S., 41, 189-205, 2005.

Johnsen, S. J., Dahl-Jensen, D., Gundestrup, N., Steffensen, J. P., Clausen, H. B., Miller, H., Masson-Delmotte, V., Sveinbjörnsdottir, A. E., and White, J.: Oxygen isotope and palaeotemperature records from six Greenland ice-core stations: Camp Century, Dye-3, GRIP, GISP2, Renland and NorthGRIP, J. Quaternary Sci., 16, 299-307, 2001.

Johnson, J. A., Mason, W. P., Shturmakov, A. J., Haman, S. T., Sendelbach, P. J., Mortensen, N. B., Augustin, L. J., and Dahnert, K. R.: A new $122 \mathrm{~mm}$ electromechanical drill for deep icesheet coring (DISC): 5. Experience during Greenland field testing, Ann. Glaciol., 47, 54-60, 2007.

Jouzel, J. and Merlivat, L.: Deuterium and oxygen 18 in precipitation: modeling of the isotopic effects during snow formation, $\mathrm{J}$. Geophys. Res.-Atmos., 89, 11749-11757, 1984.

Jouzel, J., Alley, R. B., Cuffey, K. M., Dansgaard, W., Grootes, P., Hoffmann, G., Johnsen, S. J., Koster, R. D., Peel, D., Shuman, A., Stievenard, M., Stuiver, M., and White, J.: Validity of the temperature reconstruction from water isotopes in ice cores, J. Geophys. Res.-Oceans, 102, 26471-26487, 1997.

Kavanaugh, J. L. and Cuffey, K. M.: Space and time variation of $\delta^{18} \mathrm{O}$ and $\delta \mathrm{D}$ in Antarctic precipitation revisited, Global Biogeochem. Cy., 17, 1017, doi:10.1029/2002GB001910, 2003.

Kerstel, E. T., Van Trigt, R., Reuss, J., and Meijer, H. A. J.: Simultaneous determination of the ${ }^{2} \mathrm{H} /{ }^{1} \mathrm{H},{ }^{17} \mathrm{O} / 616 \mathrm{O}$, and ${ }^{18} \mathrm{O} /{ }^{16} \mathrm{O}$ isotope abundance ratios in water by means of laser spectrometry, Anal. Chem., 71, 5297-5303, 1999.

Lis, G., Wassenaar, L. I., and Hendry, M. J.: High-precision laser spectroscopy $\mathrm{D} / \mathrm{H}$ and ${ }^{18} \mathrm{O} /{ }^{16} \mathrm{O}$ measurements of microliter natural water samples, Anal. Chem., 80, 287-293, 2008.

Markle, B. R., Steig, E. J., Buizert, C., Schoenemann, S. W., Bitz, C. M., Fudge, T. J., Pedro, J. B., Ding, Q., Jones, T. R., White, J. W., and Sowers, T.: Global atmospheric teleconnections during Dansgaard-Oeschger events, Nat. Geosci., 10, 36-40, 2017.

Maselli, O. J., Fritzsche, D., Layman, L., McConnell, J. R., and Meyer, H.: Comparison of water isotope-ratio determinations using two cavity ring-down instruments and classical mass spectrometry in continuous ice-core analysis, Isot. Environ. Healt. S., 49, 387-398, 2013.

Mook, W.: Environmental Isotopes in the Hydrological Cycle, IHPV Technical Documents in Hydrology no. 39, UNESCO/IAEA, Paris/Vienna, 2000.

Osterberg, E. C., Handley, M. J., Sneed, S. B., Mayewski, P. A., and Kreutz, K. J.: Continuous ice core melter system with discrete sampling for major ion, trace element, and stable isotope analyses, Environ. Sci. Technol., 40, 3355-3361, 2006.

Petit, J. R., Jouzel, J., Raynaud, D., Barkov, N. I., Barnola, J. M., Basile, I., Bender, M., Chappellaz, J., Davis, M., Delaygue, G., and Delmotte, M.: Climate and atmospheric history of the past 420000 years from the Vostok ice core, Antarctica, Nature, 399, 429-436, 1999.

Rhodes, R. H., Faïn, X., Stowasser, C., Blunier, T., Chappellaz, J., McConnell, J. R., Romanini, D., Mitchell, L. E., and Brook, E. J.: Continuous methane measurements from a late Holocene Greenland ice core: Atmospheric and in-situ signals, Earth Planet. Sc. Lett., 368, 9-19, 2013. 
Röthlisberger, R., Bigler, M., Hutterli, M., Sommer, S., Stauffer, B., Junghans, H. G., and Wagenbach, D.: Technique for continuous high-resolution analysis of trace substances in firn and ice cores, Environ. Sci. Technol., 34, 338-342, 2000.

Sharp, Z. D., Atudorei, V., and Durakiewicz, T.: A rapid method for determination of hydrogen and oxygen isotope ratios from water and hydrous minerals, Chem. Geol., 178, 197-210, 2001.

Steig, E. J., Ding, Q., White, J. W. C., Kuttel, M., Rupper, S. B., Neumann, T. A., Neff, P. D., Gallant, A. J. E., Mayewski, P. A., Taylor, K. C., Hoffmann, G., Dixon, D. A., Schoenemann, S. W., Markle, B. R., Fudge, T. J., Schneider, D. P., Schauer, A. J., Teel, R. P., Vaughn, B. H., Burgener, L., Williams, J., and Korotkikh, E.: Recent climate and ice-sheet changes in West Antarctica compared with the past 2000 years, Nat. Geosci., 6, 372-375, 2013.
Vaughn, B. H., White, J. W. C., Delmotte, M., Trolier, M., Cattani, O., and Stievenard, M.: An automated system for hydrogen isotope analysis of water, Chem. Geol., 152, 309-319, 1998.

WAIS Divide Project Members: Precise interpolar phasing of abrupt climate change during the last ice age, Nature, 520, 661-665, 2015.

Witte, H. and Barnes, R. M. (Ed.): Emission Spectroscopy Dowden, Hutchinson und Ross, Inc. Stroudsburg, Pennsylvania distributed by Halsted Press, 548 pp., doi:10.1002/bbpc.19760801140, 1976. 